\title{
COST OPTIMIZATION OF TWO-STAGE HELICAL GEARBOXES WITH SECOND STAGE DOUBLE GEAR-SETS
}

\author{
Le Hoang Anh \\ Faculty of Mechanical Engineering \\ Vinh Long University of Technology Education \\ 73 Nguyen Hue str., Ward 2, Vinh Long City, Vinh Long province, 85000 \\ Nguyen Hong Linh \\ Faculty of Mechanical and Power Engineering \\ Electric Power University \\ 235 Hoang Quoc Viet str., Bac Tu Liem District, Hanoi, 100000 \\ Nguyen Huu Quang \\ Faculty of Mechanical Engineering ${ }^{l}$ \\ Pham Duc Lam \\ Faculty of Mechanical, Electrical, Electronic and Automotive Engineering \\ Nguyen Tat Thanh University \\ 300A Nguyen Tat Thanh, Ward 13, Dist. 4, Ho Chi Minh City, 72820 \\ Nguyen Anh Tuan \\ Faculty of Mechanical Engineering ${ }^{l}$ \\ Nguyen Khac Tuan \\ Faculty of Automotive and Power Machinery Engineering ${ }^{2}$ \\ Nguyen Thi Thanh Nga \\ Faculty of Mechanical Engineering ${ }^{2}$ \\ Vu Ngoc Pi $\bowtie$ \\ Faculty of Mechanical Engineering ${ }^{2}$ \\ vungocpi@tnut.edu.vn \\ ${ }^{1}$ University of Economics - Technology for Industries \\ 456 Minh Khai Street, Vinh Tuy ward, Hai Ba Trung District, Hanoi, 11622 \\ ${ }^{2}$ Thai Nguyen University of Technology \\ 3/2 str., Tich Luong Ward, Thai Nguyen City, Vietnam, 251750
}

$\triangle$ Corresponding author

\begin{abstract}
In practice, the cost of a gearbox plays a very important role in the trade. Therefore, reducing the cost of gearboxes is an important task not only when manufacturing the gearboxes but also when designing them. In order to reduce the cost of a gearbox, there are many solutions in which determining the optimal partial gear ratios of a gearbox is an effective measure. This is because it not only the size, the mass but also the cost of a gearbox depends greatly on the partial gear ratios. This work presents a method for calculating the cost function of two-stage helical gearboxes with second-stage double gear-sets based on the mass of the components that construct the gearbox. The cost objective function is minimized to achieve the optimal transmission ratios. Furthermore, screening experiments are carried out with nine important input parameters that have significant effects on the optimum transmission ratio of the second stage. These parameters are the total gearbox ratio, the coefficient of wheel face width of the first stage, coefficient of wheel face width of the second stage, the allowable contact stress of the first stage, the allowable contact stress of the second stage, the output torque, the cost of gearbox housing, the cost of gears, and the shaft cost. The experimental results of were analysed by using the Analysis of Variance (ANOVA) method with the help of Minitab 19 software. The results demonstrate that the effective weight of the input parameters and their interactions on the output response was investigated. Also, a regression model for computing
\end{abstract}


the optimal transmission ratio of the second stage was proposed. This brings significance not only in the design process but also in manufacturing since the gearbox cost can decrease.

Keywords: cost optimization, optimization design, gear ratios, optimal gear ratios, helical gearbox.

DOI: $10.21303 / 2461-4262.2021 .001855$

\section{Introduction}

Among many drive systems used in industries such as mechanical drive systems, electric drive systems, pneumatic drives, hydraulic drives, etc., mechanical drive systems are used most widely. This is because it has simple structure, easy design and manufacture, stable working, high reliability and low cost. A mechanical drive system is responsible for reducing the rotational speed and increasing the torque from the motor shaft to the shaft of the working machine. Usually, it is composed of an electric motor, a gearbox, an external transmission drive (either a V-belt or a chain drive) and a coupling of which the gearbox is the main part. Therefore, the optimal gearbox design is a very important problem when designing a mechanical drive system. In the optimal design of a gearbox, determining the optimal gear ratios is a decisive problem because the gear ratios is the factor that has the greatest influence on the size, the volume, the mass as well as the cost of the gearbox. Fig. 1 [1] is an example for illustration of the importance of determining the optimum gear ratios for a two-stage helical gearbox. In this figure, the relationship between the mass of all gears in the gearbox and the gear ratio of the second stage $u_{2}$ is described. It is easy to known that the gear mass depends greatly on the gear ratio $u_{2}$. When $u_{2}$ is equal to 2 (the optimal value of $u_{2}$ ), the mass of the gear is only approximately $178 \mathrm{~kg}$ while it will be about $275 \mathrm{~kg}$ when $u_{2}=6$. Therefore, determining the optimum gear ratios for gearboxs is a topic that attracts the attention of many researchers.

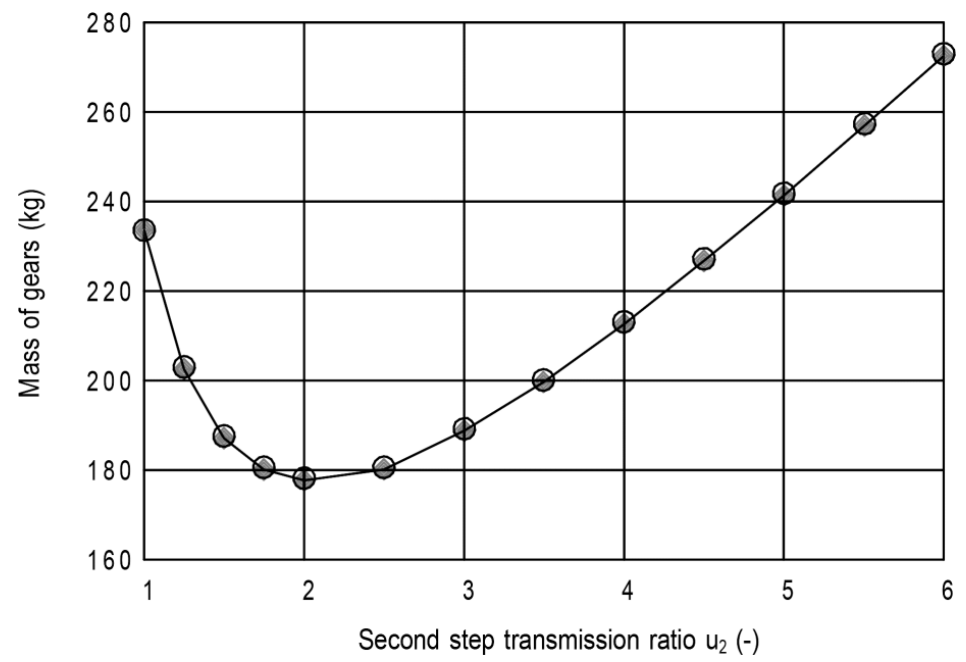

Fig. 1. Relation between gear mass and gear ratio of second stage [1]

Up to now, the optimal gear ratio of a gearbox has been determined using various methods such as using graphs [2,3], using «practical formulas» [4] which have been found based on the results from gearbox companies, or using optimal models $[5,6]$. In addition, the problem of calculating the optimal gear ratio has been performed for different types of gearboxes such as helical gear boxes [6-8], bevel gear boxes [9-11], worm gearboxes [12-15]. Besides, the optimal gear ratios have been determined for two-stage [7, 8, 14], three-stage [6, 10, 11], and four-stage gearboxes [16, 17]. Also, different objectives have also been selected when solving this problem such as the minimum mass of gears [16, 18], minimum mass of gearbox [19], the minimum gearbox cross-section section $[8,10,14]$, the minimum gearbox length [17, 20], or minimum gearbox cost $[9,21]$.

Regarding two-stage helical gearboxes, there have been several studies for determining the optimal gear ratios for two- stage helical gearboxes with second stage double gear-sets. However, 
up to now, there has been no research to determine the optimum gear ratios to achieve the minimum gearbox cost for this type of gearboxes.

From previous researches, it can realize that there have been many studies in determination of optimum gear ratios of different types of gearboxes. However, until now, the cost objective function has not been found for design of two-stage helical gearboxes with second stage double gear-sets. In this study, a method for calculating the optimum gear ratios of two-stage helical gearboxes with second stage double gear-sets is presented with novelties as the following:

1) a general cost object function was investigated;

2) significant effects of the main design parameters and their interactions on the gear ratios were evaluated;

3) a regression model was found to simply compute the optimal gear ratios by the main design parameters.

\section{Materials and methods}

\section{1. Optimization problem}

In general, the cost of gearboxes depends on the cost of main components that construct gearboxes, such as the cost of gears, shafts, rolling bearings, and gearbox housing. Moreover, the cost of these components is evaluated by used materials, manufacturing methods, heat treatment, operators, etc. According to commerce, the price of each component can be calculated by unit price per kilogram. Therefore, the cost function of a gearbox denoted by $C_{g b}$, can be computed as:

$$
C_{c g}=\sum_{i=1}^{n} c_{i} m_{i}
$$

where $c_{i}$ and $m_{i}$ are the cost per kilogram and mass of each component, respectively. In this work, three main components that powerfully affect the cost of gearboxes, such as the cost of gears, the shaft cost, and the gearbox housing cost are taken into consideration. The rolling bearing is ignored since this component is standard and is selected depending on the diameter calculation of the shafts in the design process. The gear cost, the shaft cost, and the gearbox housing cost per kilogram (USD $/ \mathrm{kg}$ ) are denoted by $c_{g}, c_{s}$ and $c_{g h}$, respectively. Similarly, the gear mass, the shaft mass, and the gearbox housing mass $(\mathrm{kg})$ are denoted by $m_{g}, m_{s}$ and $m_{g h}$ respectively. Therefore, (1) can be rewritten as:

$$
C_{c g}=c_{g} m_{g}+c_{s} m_{s}+c_{g h} m_{g h}
$$

As shown in (2), the masses of gears, the shafts, and the gearbox housing are considered for computing the gearbox mass in order to determine the gearbox cost. Fig. 2 presents the diagram of two-stage helical gearboxes with second stage double gear-set for calculating the mass of the main components.

For the two-stage helical gearboxes with the second stage double gear-set as shown in Fig. 2, the first stage has a couple gear-set and the second stage has two similar couple gear-sets. The total mass of gears is therefore computed by:

$$
m_{g}=m_{g 1}+2 m_{g 2}
$$

where $m_{g 1}$ and $m_{g 2}$ are the gear mass of the first and the second stages of the gearbox (kg). The mass of each gear can be calculated by multiplying the weight density and the volume of gear. Therefore, the gear mass of the first and the second stages, denoted by $m_{g 1}$ and $m_{g 2}$, can be respectively expressed as:

$$
\begin{aligned}
& m_{g 1}=\rho_{g} \cdot\left(\pi \cdot e_{1} \cdot d_{w 11}^{2} \cdot b_{w 1} / 4+\pi \cdot e_{2} \cdot d_{w 21}^{2} \cdot b_{w 1} / 4\right), \\
& m_{g 2}=\rho_{g} \cdot\left(\pi \cdot e_{1} \cdot d_{w 12}^{2} \cdot b_{w 2} / 4+\pi \cdot e_{2} \cdot d_{w 22}^{2} \cdot b_{w 2} / 4\right) .
\end{aligned}
$$




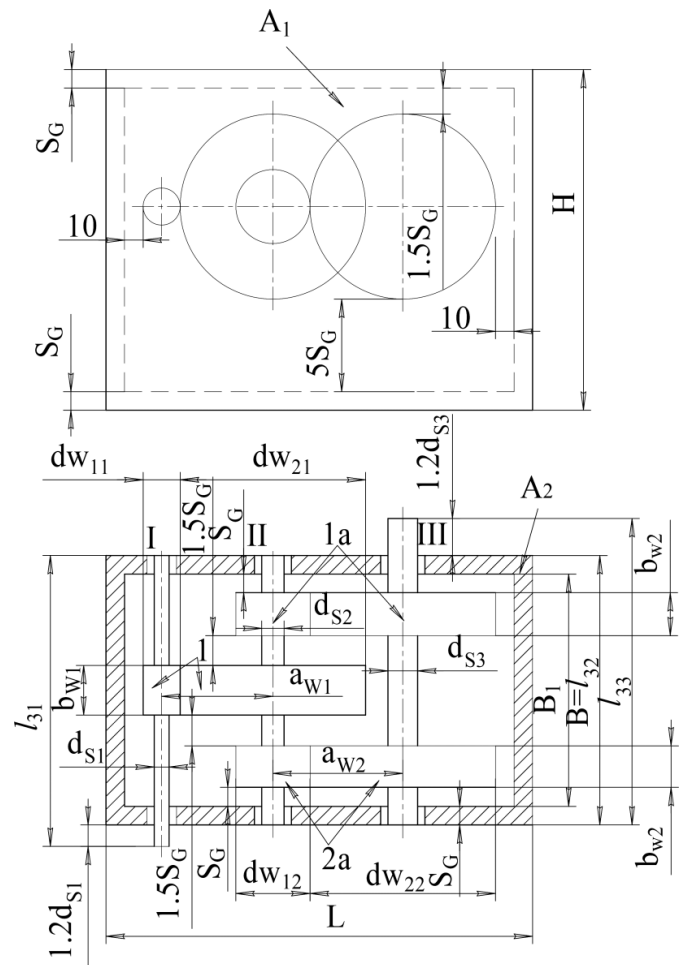

Fig. 2. Diagram of two-stage helical gearboxes with second stage double gear-set

In (4), (5), $\rho_{g}$ is the weight density of gear material, $\rho_{g}=7.82\left(\mathrm{~kg} / \mathrm{m}^{3}\right)$ when the material is steel [22]; $e_{1}$ and $e_{2}$ are respectively the volume coefficients of the drive and driven gears, $e_{1}=1$, $e_{2}=0.6[3] ; b_{w 1}$ and $b_{w 2}$ are respectively the gear width of the first and second stages (mm). They can be computed as [3]:

$$
\begin{aligned}
& b_{w 1}=X_{b a 1} \cdot a_{w 1}, \\
& b_{w 2}=X_{b a 2} \cdot a_{w 22},
\end{aligned}
$$

in which, $X_{b a 1}$ and $X_{b a 2}$ are the coefficients of wheel face width of the first and second stages, respectively; $a_{w 1}$ and $a_{w 2}$ are the center distances of the first and second stages. They can be calculated by [3]:

$$
\begin{aligned}
& a_{w 1}=k_{a}\left(u_{1}+1\right) \sqrt[3]{T_{11} k_{H \beta 1} /\left(\left[\sigma_{H 1}\right]^{2} u_{1} X_{b a 1}\right)}, \\
& a_{w 2}=k_{a}\left(u_{2}+1\right) \sqrt[3]{T_{12} k_{H \beta 2} /\left(\left[\sigma_{H 2}\right]^{2} u_{2} X_{b a 2}\right)} .
\end{aligned}
$$

All the parameters in (8), (9) are described as the following:

$-k_{a}$ is the material coefficient, $k_{a}=43$ for steel material;

$-k_{H \beta 1}$ and $\mathrm{k}_{\mathrm{H} \beta 2}$ are respectively the contacting load ratios for pitting resistance; for the first stage of a two-stage helical reducer with second stage double gear-sets $k_{H \beta 1}=1.0 \div 1.06$ [3]; for the second stage, $k_{H \beta 1}=1.02 \div 1.28$ [3]. Therefore, $\mathrm{k}_{\mathrm{H} \beta 1}$ and $k_{H \beta 2}$ can be respectively chosen as $k_{H \beta 1}=1.03$ and $k_{H \beta 2}=1.15$;

$-\left[\sigma_{H 1}\right]$ and $\left[\sigma_{H 2}\right]$ are the allowable contact stress of the first and second stages (MPa), respectively;

$-u_{1}$ and $u_{2}$ are respectively the transmission ratios of the first and second stages;

$-T_{11}$ and $T_{12}$ are respectively the torque on the first and second shafts of the gearbox ( $\left.\mathrm{Nmm}\right)$. They can be computed as: 


$$
\begin{gathered}
T_{11}=T_{\text {out }} /\left(u_{t} \cdot \eta_{h g}^{2} \cdot \eta_{b e}^{3}\right), \\
T_{12}=T_{\text {out }} /\left(2 u_{t} \cdot \eta_{h g} \cdot \eta_{b e}^{3}\right),
\end{gathered}
$$

where $u_{t}$ is the total ratio of the gearbox; $\eta_{h g}$ is the efficiency of helical gear set $\eta_{h g}=0.96 \div 0.98$ [3]; $\eta_{b e}$ is the efficiency of a rolling bearing pair $\eta_{b e}=0.99 \div 0.995$ [3].

For using in the same way as the gear mass calculation, the total mass of all shafts of the gearbox as shown in Fig. 2 can be computed as:

$$
m_{s}=m_{s 1}+m_{s 2}+m_{s 3}
$$

where $m_{s 1}, m_{s 2}$, and $m_{s 3}$ are respectively the mass of shaft 1,2 and 3 of the gearbox $(\mathrm{kg})$. They can be expressed as:

$$
\begin{aligned}
& m_{s 1}=\rho_{s} \cdot \pi \cdot d_{s 1}^{2} \cdot l_{s 1} / 4, \\
& m_{s 2}=\rho_{s} \cdot \pi \cdot d_{s 2}^{2} \cdot l_{s 2} / 4, \\
& m_{s 3}=\rho_{s} \cdot \pi \cdot d_{s 3}^{2} \cdot l_{s 3} / 4 .
\end{aligned}
$$

In (13) $-(15), \rho_{\mathrm{s}}$ is the weight density of shaft material $\left(\mathrm{kg} / \mathrm{m}^{3}\right) ; l_{s 1}, l_{s 2}$, and $l_{s 3}$ are respectively the length of shaft 1,2 and 3 of the gearbox as shown in Fig. 2. They can be written as:

$$
\begin{gathered}
l_{s 1}=B+1.2 \cdot d_{s 1}, \\
l_{s 2}=B, \\
l_{s 3}=B+1.2 \cdot d_{s 3} .
\end{gathered}
$$

In (16)-(18), preliminary diameters of the first, second and third shafts i.e., $d_{s 1}, d_{s 2}$, and $d_{s 3}$ are described as:

$$
\begin{aligned}
& d_{s 1}=\left[T_{11} /(0.2 \cdot[\tau])\right]^{1 / 3}, \\
& d_{s 2}=\left[T_{12} /(0.2 \cdot[\tau])\right]^{1 / 3}, \\
& d_{s 3}=\left[T_{13} /(0.2 \cdot[\tau])\right]^{1 / 3},
\end{aligned}
$$

where $[\tau]$ is the allowable shear stress $(\mathrm{MPa}),[\tau]=15 \div 20 \mathrm{MPa}[23]$; it can be chosen as $[\tau]=17 \mathrm{Mpa}$; $T_{11}$ and $T_{12}$ are respectively presented in (10), (11); $T_{13}$ can be expressed as:

$$
T_{13}=T_{\text {out }} /\left(u_{t} \cdot \eta_{\text {be }}\right)
$$

The mass of gearbox housing can be calculated as the similar procedure:

$$
m_{g h}=\rho_{g h} \cdot V_{g h} .
$$

In here, $\rho_{g h}$ is the weight density of gearbox housing material made by cast iron materials, $\rho_{g h}=7.2 \mathrm{~kg} / \mathrm{m}^{3}$ for the cast iron material [22]; $V_{g h}$ is the volume of the gearbox housing $\left(\mathrm{m}^{3}\right)$. For calculating $V_{g h}$, the volume gearbox housing can be divided into three parts i.e., $V_{A 1}$ is the volume of the font and back sides of the gearbox; $V_{A 2}$ is the volume of the left and right sides, and $V_{b}$ is the volume of the top and bottom sides. Therefore, $V_{g h}$ can be written as. 
In which, $V_{A 1}, V_{A 2}$ and $V_{b}$ can be described as:

$$
\begin{gathered}
V_{A 1}=L \cdot H \cdot S_{G}, V_{A 2}=B_{1} \cdot H \cdot S_{G}=\left(B-2 S_{G}\right) \cdot H \cdot S_{G}, \\
V_{b}=L \cdot B \cdot S_{G} .
\end{gathered}
$$

In (24), $L, H, S_{G}$ and $B$ can be calculated as [23]:

$$
\begin{gathered}
L=\left(d_{w 11}+d_{w 21} / 2+d_{w 12} / 2+d_{w 22}+22.5\right) / 0.975, \\
H=\max \left(d_{w 21} ; d_{w 22}\right)+6.5 \cdot S_{G}, \\
S_{G}=0.005 \cdot L+4.5, \\
B=b_{w 1}+2 \cdot b_{w 2}+7 \cdot S_{G} .
\end{gathered}
$$

The parameters $d_{\varpi 11}, d_{\varpi 21}, d_{\varpi 12}, d_{\varpi 22}$ in (25) and (26) are the gear pitch diameters of the first and second stages. They can be expressed as [3]:

$$
\begin{gathered}
d_{w 11}=2 \cdot a_{w 1} /\left(u_{1}+1\right), \\
d_{w 21}=2 \cdot a_{w 1} \cdot u_{1} /\left(u_{1}+1\right), \\
d_{w 12}=2 \cdot a_{w 2} /\left(u_{2}+1\right), \\
d_{w 22}=2 \cdot a_{w 2} \cdot u_{2} /\left(u_{2}+1\right),
\end{gathered}
$$

From the above procedure of the gearbox cost, it can be observed that all calculation parameters of the gearbox cost depend on the transmission ratio of the two stages in the gearbox, i.e., $u_{1}$, and $u_{2}$. In design process, a designer would choose reasonable transmission ratios for each type of gearbox in order to obtain the lowest gearbox cost. Therefore, the objective function as shown in eq. (2) must be minimized as follows:

$$
\text { Minimize } C_{g b} \text {, }
$$

where $C_{g b}$ can be expressed as a function depending on the transmission ratios of the two stages, i.e., $u_{1}$ and $u_{2}$ in the gearbox:

$$
C_{g b}=c_{g b}\left(u_{1}, u_{2}\right)
$$

Subject to the following constraints:

$$
1 \leq u_{1} \leq 9 \text { and } 1 \leq u_{2} \leq 9
$$

Besides, the total ratio of the gearbox $u_{t}$ has the relation with the transmission ratio of the two stages by:

$$
u_{t}=u_{1} \cdot u_{2}
$$

As it is known that $u_{t}$ should be used in the interval $[5,45]$, from (33), the objective function in (31) can be rewritten as:

$$
\text { Minimize } C_{g b}=C_{g b}\left(u_{2}\right) \text {. }
$$




\section{2. Experimental procedures}

(34) was solved by a computer program to obtain the optimal transmission ratios of the two stages. In addition, a screening experiment was conducted to illustrate the effect of input parameters on the optimal transmission ratio $u_{2}$. As the procedure in Sec. 2, the input parameters including the total gearbox ratio $u_{t}$, the coefficients of wheel face width of the first and second stages $X_{b a 1}, X_{b a 2}$, the allowable contact stress of the first and second stages $A S_{1}, A S_{2}$, the output torque $T_{\text {out }}$, the cost of gearbox housing $c_{g h}$, the cost of gears $c_{g}$, and the cost of shaft $\mathrm{c}_{\mathrm{s}}$ were considered to design the experiment. The nine input parameters and their value range are presented in Table 1. Normally, the full factorial design is 29 to denote the number of test runs in the simulation experiment; however, using Minitab 19 for the conducting experiments, the total of test runs with $1 / 4$ fraction is $29-2$, i.e., 128 test runs. The factorial design of the input parameters and the output respond $\mathrm{u}_{2}$ is illustrated in Table 2.

Table 1

Input parameters and their value range

\begin{tabular}{lcccc}
\hline \multicolumn{1}{c}{ Factor } & Code & Unit & Low & High \\
\hline Total gearbox ratio & $\mathrm{u}_{\mathrm{t}}$ & - & 5 & 45 \\
Coefficient of wheel face width of stage 1 & $X_{b a 1}$ & - & 0.3 & 0.35 \\
Coefficient of wheel face width of stage 2 & $X_{b a 2}$ & - & 0.35 & 0.4 \\
Allowable contact stress of stage 1 & $A S_{1}$ & $\mathrm{MPa}$ & 350 & 420 \\
Allowable contact stress of stage 2 & $A S_{2}$ & $\mathrm{MPa}$ & 350 & 420 \\
Output torque & $T_{\text {out }}$ & $\mathrm{Nmm}$ & 100 & 10000 \\
Cost of gearbox housing & $c_{g h}$ & $\mathrm{USD} / \mathrm{kg}$ & 1 & 5 \\
Cost of gears & $c_{g}$ & $\mathrm{USD} / \mathrm{kg}$ & 2 & 9 \\
Cost of shafts & $\mathrm{c}_{\mathrm{s}}$ & $\mathrm{USD} / \mathrm{kg}$ & 1.5 & 5
\end{tabular}

Table 2

Factorial design of the input parameters and output response

\begin{tabular}{ccccccccccc}
\hline RunOrder & $\boldsymbol{u}_{\boldsymbol{t}}$ & $\boldsymbol{X}_{\boldsymbol{b a} \mathbf{1}}$ & $\boldsymbol{X}_{\boldsymbol{b a} \mathbf{2}}$ & $\boldsymbol{A S}_{\mathbf{1}}$ & $\boldsymbol{A \boldsymbol { S } _ { \mathbf { 2 } }}$ & $\boldsymbol{T}_{\boldsymbol{o u t}}$ & $\boldsymbol{C}_{\boldsymbol{g h}}$ & $\boldsymbol{C}_{\boldsymbol{g}}$ & $\boldsymbol{C}_{\boldsymbol{s}}$ & $\boldsymbol{u}_{\mathbf{2}}$ \\
\hline 1 & 5 & 0.3 & 0.4 & 350 & 420 & 10000 & 5 & 9 & 1.5 & 4.07 \\
2 & 45 & 0.3 & 0.35 & 350 & 420 & 10000 & 1 & 2 & 1.5 & 8.49 \\
3 & 5 & 0.35 & 0.35 & 350 & 420 & 10000 & 1 & 9 & 5 & 4.46 \\
4 & 5 & 0.3 & 0.4 & 350 & 350 & 10000 & 5 & 9 & 5 & 4.00 \\
5 & 5 & 0.35 & 0.4 & 420 & 420 & 100 & 1 & 2 & 5 & 4.85 \\
6 & 5 & 0.35 & 0.35 & 420 & 350 & 100 & 1 & 9 & 5 & 13.97 \\
$\ldots$ & $\ldots$ & $\ldots$ & $\ldots$ & $\ldots$ & $\ldots$ & $\ldots$ & $\ldots$ & $\ldots$ & $\ldots$ & $\ldots$ \\
127 & 45 & 0.3 & 0.35 & 420 & 350 & 100 & 5 & 9 & 5 & 6.41 \\
128 & 45 & 0.35 & 0.4 & 350 & 420 & 10000 & 5 & 2 & 5 & 8.41
\end{tabular}

\section{Results and discussions}

After conducting the screening experiments, the results are presented as the following sections.

\section{1. Effect of input parameters on optimumtransmission ratio}

Based on the screening experiment as discussed in section 3, the main effects of each factor on the optimal transmission ratio $u_{2}$ are presented in Fig. 2. From the observation of the slope angles of all straight lines in this figure, the total gearbox ratio $u_{t}$ has the largest influence on the optimum transmission ratio $u_{2}$. Besides, the effect of these parameters on the optimum transmission ratio is much smaller than the influence of the total gearbox ratio. It is also seen from the lines of $X_{b a 1}, X_{b a 2}$, and $c_{g}$ that the coefficients of wheel face width of the first and second stages $X_{b a 1}$, $X_{b a 2}$, and the cost of gears $c_{g}$ have much less significant effect on the optimum transmission ratio. 


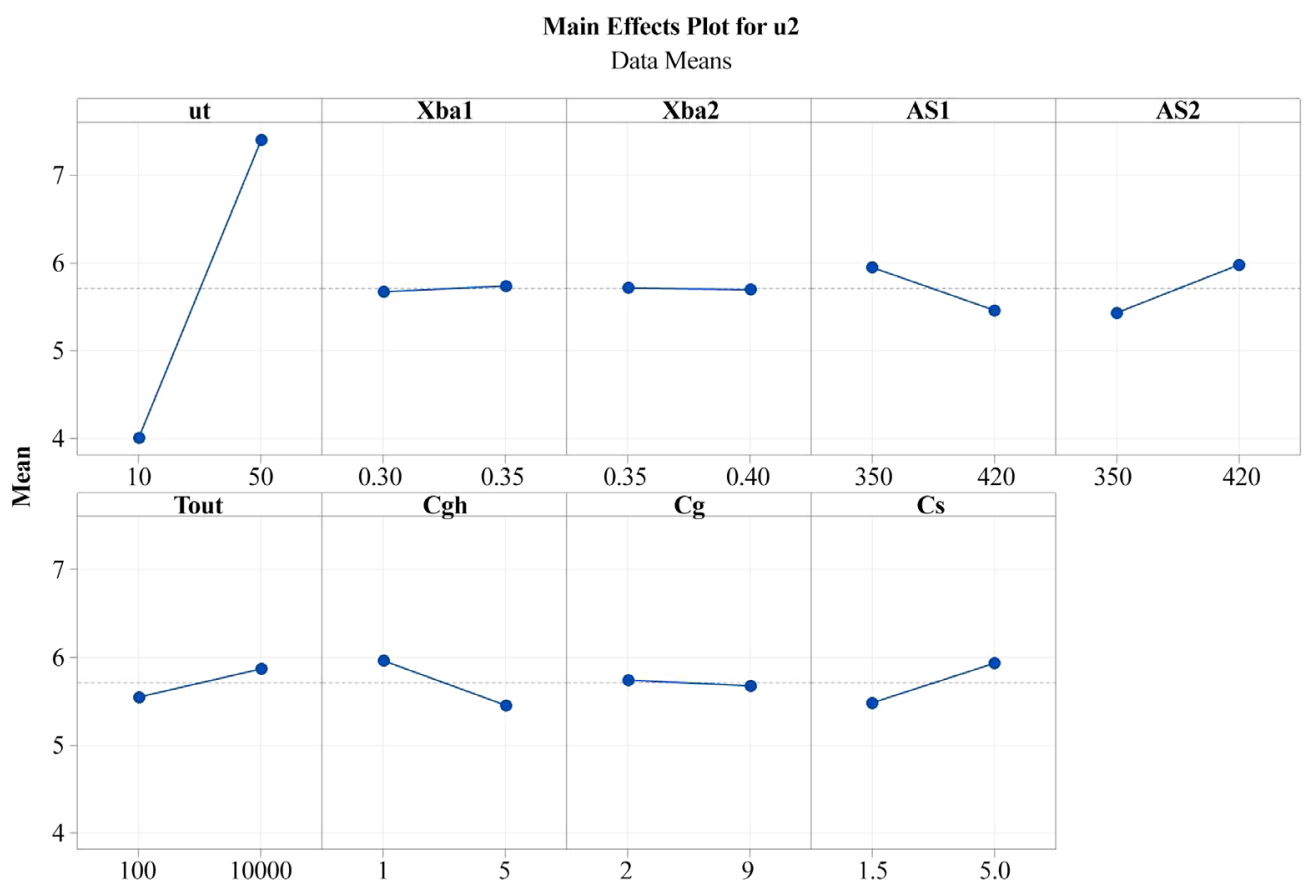

Fig. 3. Effects of the input parameters on the transmission ratio $u_{2}$

The influence of the input parameters can be seen more clearly in Fig. 4, which shows the Pareto chart of the standardized effects. For the respond model, the parameters are statistically significant at the 0.05 level. The magnitude of the effect of the input parameters on the optimal transmission ratio is arranged from the lowest value to the highest value. The strongest influence on the optimum transmission ratio $u_{2}$ comes from the total gearbox ratio $u_{t}$ (factor $A$ in Fig. 4). The effect is gradually reduced in the sequence of the remaining parameters i.e., the allowable contact stress of the second stages $A S_{2}$ (factor $E$ ), the cost of gearbox housing $c_{g h}$ (factor $G$ ), the allowable contact stress of the first stages $A S_{1}$ (factor $D$ ), the cost of shaft $c_{S}$ (factor $J$ ), the output torque $T_{\text {out }}$ (factor $F$ ), the coefficient of wheel face width of the first stage $X_{b a 1}$ (factor $B$ ), the cost of gears $c_{g}$ (factor $H$ ), the coefficient of wheel face width of the second stage $X_{b a 2}$ (factor $C$ ).

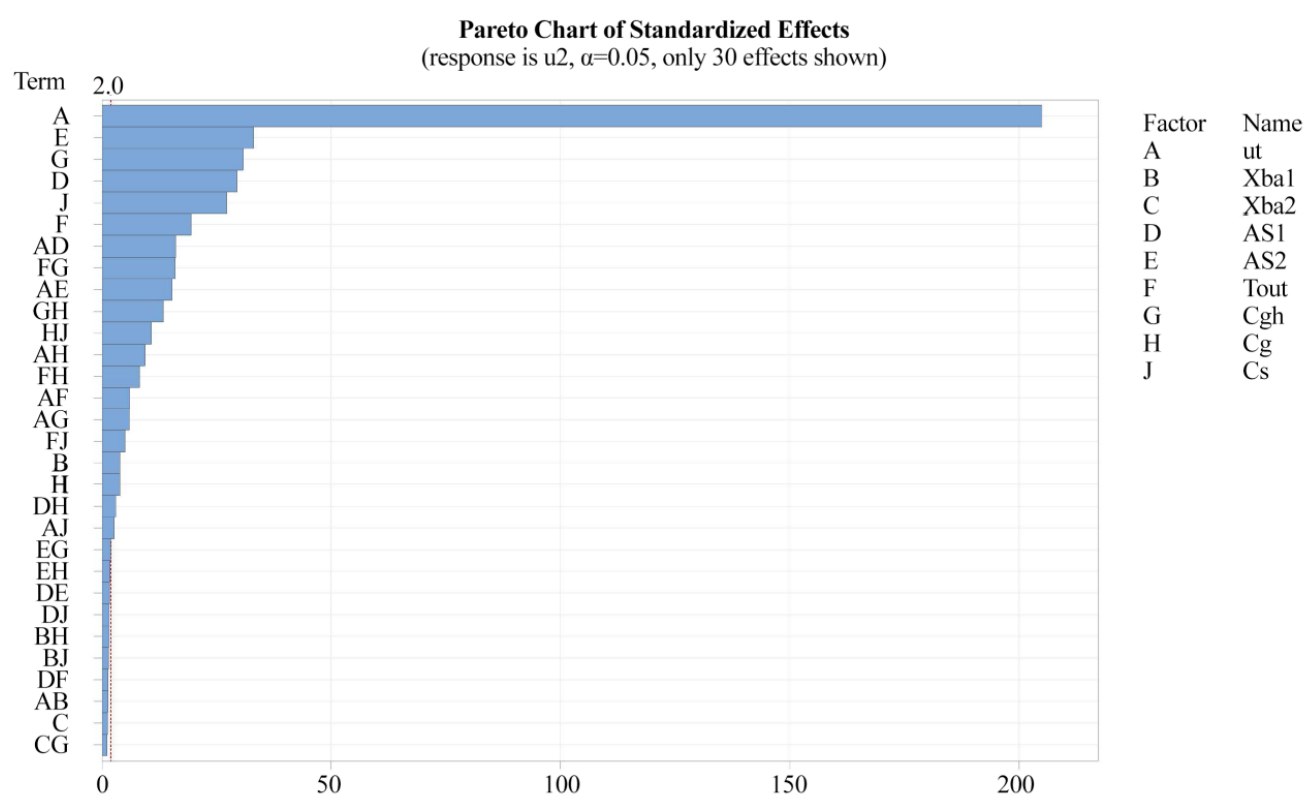

Fig. 4. Magnitude of the effect of the input parameters on the optimal transmission ratio $u_{2}$ 
In order to examine the increase and decrease of the optimum transmission ratio $u_{2}$, Fig. 5 shows the normal plot of the standardized effects. As shown in the Fig. 5, the positive influences of the four input parameters on the output respond, i.e., the total gearbox ratio $u_{t}$ (factor $A$ ), the allowable contact stress of the second stages $A S_{2}$ (factor $E$ ), the cost of shaft $c_{s}$ (factor $J$ ), and the output torque $T_{\text {out }}$ (factor $F$ ) increase the optimal transmission ratio $u_{2}$ when these parameters are varied from the low value to high value.

However, the negative effects of the two factors, i.e., the allowable contact stress of the first stages $A S_{1}$ (factor $D$ ) and the cost of gearbox housing $c_{g h}$ (factor $G$ ) reduce the optimum transmission ratio $u_{2}$.

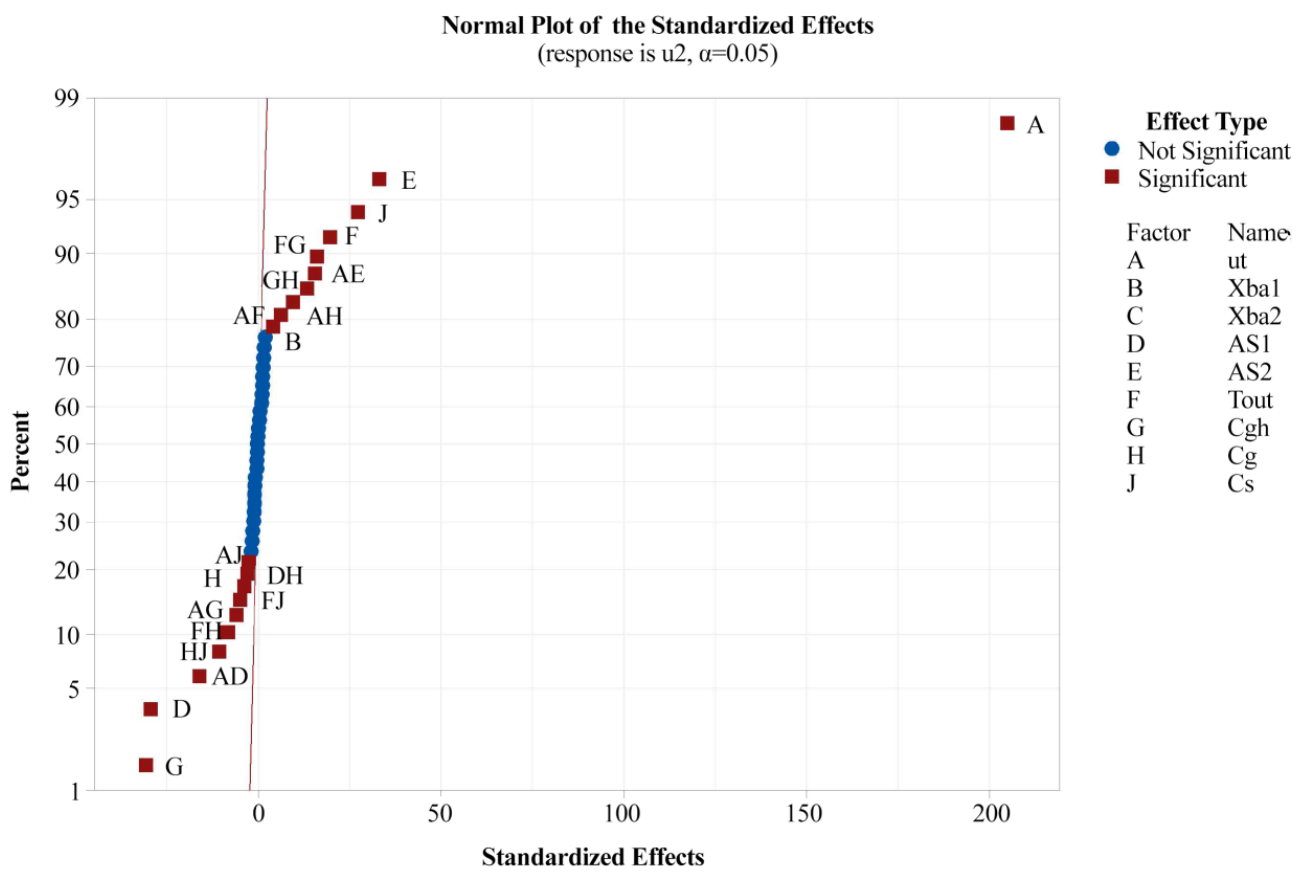

Fig. 5. Distribution of the standardized effects of the input parameters on $u_{2}$

\section{2. Regression analysis}

The regression analysis of the input parameters and their interactions with the significant effects on the optimum transmission ratio is displayed in Table 3. As seen in the second column of this table, the positive and negative values show more clearly the increasing and decreasing influences of the input parameters and their interactions. In addition, the magnitudes of these factors describe the effective weight on the optimum transmission ratio, e.g., $u_{t}$ has the largest effect on $u_{2}$. Ignoring the factors that have the insignificant effects with P-Values smaller than the statistically significant value, i.e., $\alpha=0.05$, brings the weighty effect to the output respond. This illustrates the reliability of the factors importantly affecting the optimum transmission ratio.

Furthermore, the coefficients of the input parameters and their interactions are also presented in the third column of Table 3. In order to simply compute the optimum transmission ratio of the second stage, the regression equation can be expressed as the following model:

$$
\begin{aligned}
& u_{2}=1.964+0.08476 u_{t}+1.329 X_{b a 1}-0.001078 A S_{1}+0.004015 A S_{2}+ \\
& +0.000017 T_{\text {out }}-0.1576 C_{g h}+0.0641 C_{g}+0.2497 C_{s}-0.000189 u_{t} \cdot A S_{1}+ \\
& +0.000182 u_{t} \cdot A S_{2}+0.000001 u_{t} \cdot T_{\text {out }}-0.001236 u_{t} \cdot C_{g h}+0.001109 u_{t} \cdot C_{g}- \\
& -0.000638 u_{t} \cdot C_{s}-0.000210 A S_{1} \cdot C_{g}-0.000241 A S_{2} \cdot C_{g h}+0.000013 T_{\text {out }} \cdot C_{g h}- \\
& -0.000004 T_{\text {out }} \cdot C_{g}-0.000005 T_{\text {out }} \cdot C_{s}+0.01577 C_{g h} \cdot C_{g}-0.01465 C_{g} \cdot C_{s} .
\end{aligned}
$$


The correlation coefficients as shown in Table 4 i.e., $R^{2}=0.9977$, adj- $R^{2}=0.9972$ and pred- $\mathrm{R}^{2}=0.9966$ are almost approximate to 1 . For this, the proposed model in (35) presents a good fit to the experimental data. Therefore, based on the model, the optimum transmission ratio of the second stage $u_{2}$ is obtained. According to (33), the optimum transmission ratio of the first stage is also determined.

Table 3

Regression analysis for input parameters and their interactions

\begin{tabular}{|c|c|c|c|c|c|c|}
\hline Term & Effect & Coef & SE Coef & T-Value & P-Value & VIF \\
\hline Constant & - & 5.70803 & 0.00839 & 680.59 & 0.000 & - \\
\hline$u_{t}$ & 3.38441 & 1.69221 & 0.00839 & 201.77 & 0.000 & 1.00 \\
\hline$X_{b a 1}$ & 0.06644 & 0.03322 & 0.00839 & 3.96 & 0.000 & 1.00 \\
\hline$A S_{1}$ & -0.48779 & -0.24389 & 0.00839 & -29.08 & 0.000 & 1.00 \\
\hline$A S_{2}$ & 0.54807 & 0.27403 & 0.00839 & 32.67 & 0.000 & 1.00 \\
\hline$T_{\text {out }}$ & 0.32183 & 0.16092 & 0.00839 & 19.19 & 0.000 & 1.00 \\
\hline$c_{g h}$ & -0.50865 & -0.25432 & 0.00839 & -30.32 & 0.000 & 1.00 \\
\hline$c_{g}$ & -0.06607 & -0.03304 & 0.00839 & -3.94 & 0.000 & 1.00 \\
\hline$c_{s}$ & 0.44994 & 0.22497 & 0.00839 & 26.82 & 0.000 & 1.00 \\
\hline$u_{t} \cdot A S_{1}$ & -0.26515 & -0.13257 & 0.00839 & -15.81 & 0.000 & 1.00 \\
\hline$u_{t} \cdot A S_{2}$ & 0.25410 & 0.12705 & 0.00839 & 15.15 & 0.000 & 1.00 \\
\hline$u_{t} \cdot T_{\text {out }}$ & 0.10060 & 0.05030 & 0.00839 & 6.00 & 0.000 & 1.00 \\
\hline$u_{t} \cdot c_{g h}$ & -0.09889 & -0.04944 & 0.00839 & -5.90 & 0.000 & 1.00 \\
\hline$u_{t} \cdot c_{g}$ & 0.15526 & 0.07763 & 0.00839 & 9.26 & 0.000 & 1.00 \\
\hline$u_{t} \cdot c_{s}$ & -0.04468 & -0.02234 & 0.00839 & -2.66 & 0.009 & 1.00 \\
\hline$A S_{1} \cdot c_{g}$ & -0.05146 & -0.02573 & 0.00839 & -3.07 & 0.003 & 1.00 \\
\hline$A S_{2} \cdot c_{g h}$ & -0.03372 & -0.01686 & 0.00839 & -2.01 & 0.047 & 1.00 \\
\hline$T_{\text {out }} \cdot c_{g h}$ & 0.26418 & 0.13209 & 0.00839 & 15.75 & 0.000 & 1.00 \\
\hline$T_{\text {out }} \cdot c_{g}$ & -0.13761 & -0.06880 & 0.00839 & -8.20 & 0.000 & 1.00 \\
\hline$T_{\text {out }} \cdot c_{s}$ & -0.08454 & -0.04227 & 0.00839 & -5.04 & 0.000 & 1.00 \\
\hline$c_{g h} \cdot c_{g}$ & 0.22071 & 0.11036 & 0.00839 & 13.16 & 0.000 & 1.00 \\
\hline$c_{g} \cdot c_{s}$ & -0.17942 & -0.08971 & 0.00839 & -10.70 & 0.000 & 1.00 \\
\hline
\end{tabular}

Table 4

Summary of model for $u_{2}$

\begin{tabular}{clll}
\hline S & R-sq & R-sq(adj) & R-sq(pred) \\
\hline 0.0948864 & $99.77 \%$ & $99.72 \%$ & $99.66 \%$
\end{tabular}

In order to evaluate the reliability of the regression model more carefully as shown in (35), the normal probability and versus order plots are depicted in Fig. 6. It can be observed from Fig. 6, $\boldsymbol{a}$ that the normal plot of the residuals approximately follows a straight line. Furthermore, in Fig. 6, $\boldsymbol{b}$ the residuals are randomly distributed on both sides of the horizontal axis. These results demonstrate that the regression model is consistent with the experiment data. 

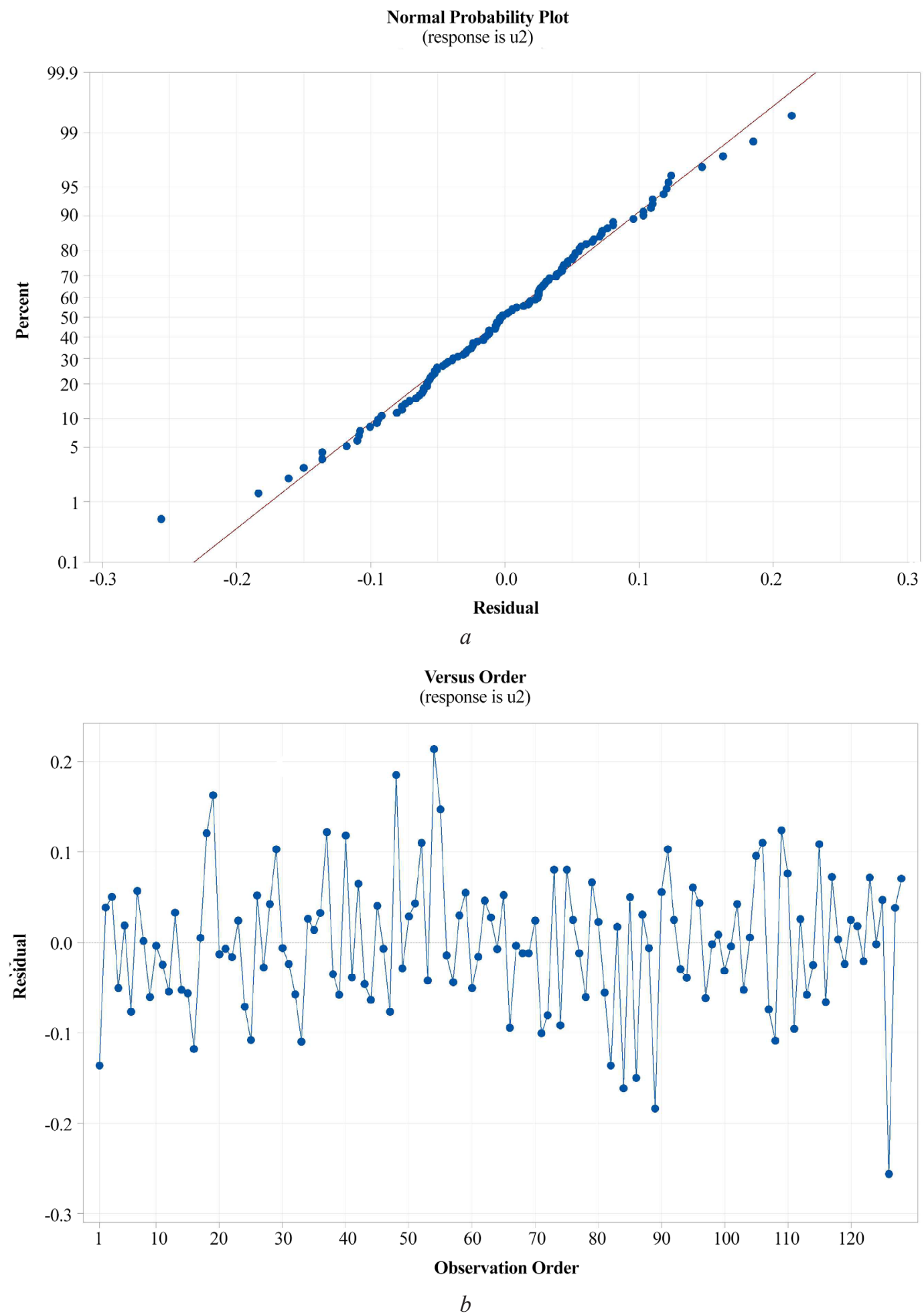

Fig. 6. Residuals versus fits: $a$ - Normal Probability, $b-$ Versus order

\section{Conclusions}

In this paper, a method for cost analysis of a two-stage helical gearbox with second stage double gear-set was proposed. The cost function was minimized in order to get the optimum transmission ratio of the stages. The Minitab 19 was used to design the experiment and analysis the results. The influence of nine input parameters including the total gearbox ratio $u_{t}$, the coefficient of wheel face width of the first and second stages $X_{b a 1}, X_{b a 2}$, the allowable contact stress of 
the first and second stages $A S_{1}, A S_{2}$, the output torque $T_{\text {out }}$, the cost of gearbox housing $c_{g h}$, gears $c_{g}$, and shaft $c_{S}$ on the optimum gear ratio was investigated. The results from the experiments clearly showed the significant influences of the input parameters and their interactions on the optimal transmission ratio $u_{2}$. It was found that the largest influence on $u_{2}$ belongs to the total gearbox ratio $u_{t}$; followed by the influence of $A S_{2}, c_{g h}, A S_{1}, c_{s}, T_{\text {out }}, X_{b a 1}, c_{g}$, and $X_{b a 2}$. Additionally, based on the regression and variance analysis, the mathematical model was achieved to calculate the optimum transmission ratio $u_{2}$. This model was well evaluated by the correlation coefficients and residual versus fits. This is greatly significant in design and manufacturing. However, the formula for determining the optimal gear ratio still does not take into account the cost of the bearings. That is also the direction of future research for scientists.

\section{Acknowledgements}

This work was supported by Thai Nguyen University of Technology (Vietnam).

\section{References}

[1] Hong, T. T., Cuong, N. V., Ky, L. H., Tuan, N. K., Pi, V. N. (2019). Calculating optimum gear ratios of two step bevel helical reducer. International Journal of Applied Engineering Research (IJAER), 14 (16), 3494-3499. Available at: https://www.ripublication.com/ijaer19/ijaerv14n16_05.pdf

[2] Kudryavtsev, V. N., Derzhavets, Yu. A., Gluharev, E. G. (1971). Design and Calculus of Gearboxes. Leningrad: Mashinostroenie Publishing, 328.

[3] Trinh Chat, L. V. U. (1996). Calculation of mechanical driven systems. Ha Noi: Education Publisher.

[4] Milou, G., Dobre, G., Visa, F., Vitila, H. (1996). Optimal design of two step gear units, regarding the main parameters. VDI Berichte, 1230, 227.

[5] Pi, V. N., Tuan, N. K., Hung, L. X., Tung, L. A. (2019). A New Study on Determination of Optimum Gear Ratios of a TwoStage Helical Gearbox. Lecture Notes in Mechanical Engineering, 107-115. doi: https://doi.org/10.1007/978-981-13-8297-0_14

[6] Pi, V. N., Tuan, N. K. (2016). Optimum Determination of Partial Transmission Ratios of Three-Step Helical Gearboxes for Getting Minimum Cross Section Dimension. Journal of Environmental Science and Engineering A, 5 (11). doi: https://doi.org/ $10.17265 / 2162-5298 / 2016.11 .004$

[7] Buiga, O., Tudose, L. (2014). Optimal mass minimization design of a two-stage coaxial helical speed reducer with Genetic Algorithms. Advances in Engineering Software, 68, 25-32. doi: https://doi.org/10.1016/j.advengsoft.2013.11.002

[8] Tuan, N. K., Pi, V. N., Thi Hong Cam, N., Thao, T. T. P., Thanh, H. K., Hung, L. X., Tham, H. T. (2018). Determining Optimal Gear Ratios of a Two-stage Helical Reducer for Getting Minimal Acreage of Cross Section. MATEC Web of Conferences, 213, 01008. doi: https://doi.org/10.1051/matecconf/201821301008

[9] Pi, V. N. (2000). A new and effective method for optimal calculation of total transmission ratio of two step bevel-helical gearboxes. Proceedings of the International Colloquium on Mechannics of Solids, Fluids, Structures \& Interaction, 716-719.

[10] Pi, V. N., Thi Phuong Thao, T., Thi Hong, T., Khac Tuan, N., Hung, L. X., Anh Tung, L. (2019). Determination of optimum gear ratios of a three stage bevel helical gearbox. IOP Conference Series: Materials Science and Engineering, 542, 012007. doi: https://doi.org/10.1088/1757-899x/542/1/012007

[11] Thao, T. T. P., Hong, T. T., Van Cuong, N., Ky, L. H., Tu, N. T., Hung, L. X., Vu, N. P. (2019). Determining Optimum Gear Ratios of Mechanical Driven Systems Using Three Stage Bevel Helical Gearbox and Chain Drive. Lecture Notes in Networks and Systems, 249-261. doi: https://doi.org/10.1007/978-3-030-37497-6_29

[12] Tung, L. A., Hong, T. T., Cuong, N. V., Ky, L. H., Tu, N. T., Hung, L. X., Vu, N. P. (2019). A Study on Determination of Optimum Gear Ratios of a Two-Stage Worm Gearbox. Lecture Notes in Networks and Systems, 76-84. doi: https://doi.org/10.1007/978-3-030-37497-6_8

[13] Cuong, N. M., Tham, H. T., Hong, T. T., Van Cuong, N., Ky, L. H., Tu, N. T. et. al. (2019). Calculation of Optimum Gear Ratios of Two-Step Worm Gearbox. Lecture Notes in Networks and Systems, 179-188. doi: https://doi.org/10.1007/978-3-030-37497-6_21

[14] Pi, V. N., Tuan, N. K., Hung, L. X., Dung, N. T. Q., Hien, B. T. (2019). Determining Optimum Gear Ratios of a Worm-Helical Gearbox for Minimum Acreage of the Cross Section. Lecture Notes in Mechanical Engineering, 89-96. doi: https://oi.org/ 10.1007/978-981-13-8297-0_12

[15] Pi, V. N., Thi Hong, T., Hung, L. X., Anh Tung, L., Khac Tuan, N. (2019). A study on determination of optimum gear ratios of a worm -helical gearbox. IOP Conference Series: Materials Science and Engineering, 635, 012010. doi: https://doi.org/ $10.1088 / 1757-899 x / 635 / 1 / 012010$ 
[16] Pi, V. N. (2008). Optimal determination of partial transmission ratios for four-step helical gearboxes with first and third step double gear-sets for minimal mass of gears. Applied Computing Conference, 53-57. Available at: http://www.wseas.us/ e-library/conferences/2008/istanbul/acc/acc_07.pdf

[17] Pi, V. N. (2008). Optimal calculation of partial transmission ratios for four-step helical gearboxes with first and thirdstep double gear-sets for minimal gearbox length. MATH'08: Proceedings of the American Conference on Applied Mathematics, 29-32.

[18] Pi, V. N. (2007). A new study on the optimal prediction of partial transmission ratios of three-step helical gearboxes with second-step double gear-sets. Wseas Transactions on Applied and Theoretical Mechanics, 2 (11), 229-238. Avaialble at: https://www.researchgate.net/profile/Vu-N/publication/237522436_A_new_study_on_the_optimal_prediction_of_partial_transmission_ratios_of_three-step_helical_gearboxes_with_second-step_double_gear-sets/links/54356dfa0cf $2 \mathrm{bf} 1 \mathrm{f} 1 \mathrm{f}$ 2b0645/A-new-study-on-the-optimal-prediction-of-partial-transmission-ratios-of-three-step-helical-gearboxes-with-second-step-double-gear-sets.pdf

[19] Golabi, S., Fesharaki, J. J., Yazdipoor, M. (2014). Gear train optimization based on minimum volume/weight design. Mechanism and Machine Theory, 73, 197-217. doi: https://doi.org/10.1016/j.mechmachtheory.2013.11.002

[20] Cam, N. T. H., Hong, T. T., Cuong, N. V., Ky, L. H., Tung, L. A., Tu, N. T. et. al. (2019). Calculating Optimum Gear Ratios of Mechanical Drive Systems Using Two-Stage Helical Gearbox with Second-Stage Double Gear Sets and Chain Drive for Minimum Gearbox Length. Lecture Notes in Networks and Systems, 155-163. doi: https://doi.org/10.1007/978-3-030-37497-6_18

[21] Vu, N.-P., Nguyen, D.-N., Luu, A.-T., Tran, N.-G., Tran, T.-H., Nguyen, V.-C. et. al. (2020). The Influence of Main Design Parameters on the Overall Cost of a Gearbox. Applied Sciences, 10 (7), 2365. doi: https://doi.org/10.3390/app10072365

[22] Density, Specific Weight and Specific Gravity. Available at: https://www.engineeringtoolbox.com/density-specificweight-gravity-d_290.html

[23] Römhild, I., Linke, H. (1992). Gezielte Auslegung Von Zahnradgetrieben mit minimaler Masse auf der Basis neuer Berechnungsverfahren. Konstruktion, 44 (7-8), 229-236.

Received date 24.05.2021

(C) The Author(s) 2021

Accepted date 10.09.2021

This is an open access article

Published date 18.11.2021 under the Creative Commons CC BY license

How to cite: Anh, L. H., Linh, N. H., Quang, N. H., Lam, P. D., Tuan, N. A., Tuan, N. K., Nga, N. T. T., Pi, V. N. (2021). Cost optimization of two-stage helical gearboxes with second stage double gear-sets. EUREKA: Physics and Engineering, 6, 89-101. doi: https://doi.org/10.21303/2461-4262.2021.001855 